\title{
Desempenho de Novilhos Nelore em Pastejo na Época das Águas: Ganho de Peso, Consumo e Parâmetros Ruminais
}

\author{
Rafael Henrique de Tonissi e Buschinelli de Goes ${ }^{1}$, Antonio Bento Mancio², Rogério de Paula \\ Lana $^{3}$, Sebastião de Campos Valadares Filho ${ }^{3}$, Paulo Roberto Cecon ${ }^{4}$, Augusto César de \\ Queiroz $^{3}$, Aloízio Moraes Lopes ${ }^{5}$
}

\begin{abstract}
RESUMO - Avaliou-se a suplementação a pasto de novilhos, durante o período das águas. O experimento foi realizado na Fazenda do Braga, em Araponga-MG, no período de janeiro a abril de 1999. Foram utilizados 24 novilhos Nelore, inteiros, com idade média de 24 meses e peso inicial de $335 \mathrm{~kg}$, e nove novilhos fistulados, em pastagens de capim-gordura (Melinis minutiflora) e capim-braquiária (Brachiaria radicans). Utilizou-se três suplementos comerciais: suplementação com sal mineral (SM), suplementação com sal proteínado à base de milho, farelo de trigo e uréia (MT), e um suplemento com sal proteínado à base de farelo de trigo e farelo de soja (TS). O delineamento utilizado foi inteiramente casualizado e as médias foram comparadas pelo teste $\mathrm{SNK}$, a $5 \%$ de probabilidade. Os animais foram divididos em grupos de oito e distribuídos em três piquetes e apresentaram ganhos de peso de 0,$60 ; 0,76$; e $0,88 \mathrm{~kg} / \mathrm{dia}$ para os suplementos SM, TS e MT, respectivamente. Não houve diferença entre médias, para os animais que receberam os dois suplementos protéicos, apresentando consumo de suplemento de 0,13;0,23; e 0,20 kg/dia, para SM, TS e MT, respectivamente. A concentração de amônia ruminal foi maior nos animais suplementados com MT e o pH, para todos os tratamentos, manteve-se acima de 6,2. Os animais recebendo suplementação protéica apresentaram melhor desempenho, quando comparados aos que receberam a SM.
\end{abstract}

Palavras-chave: braquiária, desempenho, misturas múltiplas, Nelore, suplementação nas águas, suplementos protéicos

\section{Performance of Nellore Young Bulls in the Rainy Season Period: Weight Gain, Intake and Ruminal Parameters}

\begin{abstract}
The objective was to evaluate the effect of supplemention of young bulls, under grazing, in the rainy season period. The experiment was conducted at the Braga Farm in Araponga, MG, in the period from january to april of 1999. Using twenty four young bulls with $335 \mathrm{~kg} \mathrm{LW}$ of initial body weight, and nine fistulated steers, in Gordura (Melinis minutiflora) and Brachiaria radicans grass. Three comercial supplements were used: mineral salt supplement (SM), corn-wheat meal and urea based protein supplement (MT) and wheat-soybean meal based protein supplement (TS). A completely randomized experimental design was used, the means were compared by SNK test at $5 \%$ probability. The animals, groups of eight, were allotted to three paddocks and showed average daily gain of 0.60 , 0.76 and $0.88 \mathrm{~kg} / \mathrm{animal} / \mathrm{day}$ for the SM, TS e MT, supplement. There was no difference between the protein supplements, the supplement intake was $0.13,0.23$ and $0.20 \mathrm{~kg} / \mathrm{animal} / \mathrm{day}$, for SM, TS e MT, respectively. The concentration of ruminal amonia was larger for the animals supplemented with MT and the $\mathrm{pH}$ for all treatments was manteined above 6,2 . The animals feeding protein supplement, have better performance, when compared with those feed SM.
\end{abstract}

Key Words: braquiária, multiples mixture, Nellore, performance, protein supplementation, rainy supplementation

\section{Introdução}

As pastagens representam a forma mais prática e econômica para a alimentação de bovinos, sendo a base para a bovinocultura de corte no Brasil. Existe, no entanto, a necessidade de obter ganhos em produtividade, minimizando os efeitos decorrentes da sazonalidade quantitativa e qualitativa das forrageiras tropicais (Paulino, 1999).
O consumo e a produção animal, geralmente, não estão correlacionados com o total de forragem disponível (Euclides, 1995), mas sim com a disponobilidade de MS verde. Se a digestibilidade da forrageira for baixa, o controle do consumo será feito pela distensão ruminal, associado à quantidade de aminoácidos absorvidos no intestino e aos efeitos das elevadas concentrações de ácidos graxos voláteis.

É esperado que animais a pasto consigam suprir

\footnotetext{
1 Zootecnista, Ms, estudante de Doutorado, Departamento de Zootecnia, UFV, Viçosa-MG, 36571-000. E.mail: ds38426@correio.ufv.br 2 Professor Adjunto do Departamento de Zootecnia-UFV - Viçosa-MG - 36571-000

3 Professor do Departamento de Zootecnia-UFV, pesquisador do CNPq - Viçosa-MG - 36571-000

${ }^{4}$ Professor do Departamento de Informática-UFV, bolsista do CNPq - Viçosa-MG - 36571-000.

${ }^{5}$ Estudante de Mestrado em Zootecnia - DZO - UFV.
} 
suas necessidades nutricionais, com o consumo de forragem, decorrente de sua digestibilidade e de sua qualidade (Noller et al., 1996). Na época chuvosa, é esperado que não ocorra deficiência de proteína bruta (Poppi \& Mclennan 1995), considera-se então que os valores superiores a 7-8\% de proteína suprem as necessidades dos microrganismos ruminais. Lana et al. (1998) citaram que parte desta é desaminada no rúmen, diminuindo o suprimento de proteína metabolizável no intestino delgado, devido ao alto $\mathrm{pH}$ ruminal e à alta degradabilidade, facilitando a desaminação. Minson (1990) relatou que, para as gramíneas tropicais, valores inferiores a $7 \%$ de proteína bruta limitam o crescimento dos microrganismos ruminais. A suplementação, então, surge como alternativa para a manutenção do crescimento ou do ganho de peso (Paulino et al., 1982; Paulino \& Ruas, 1988).

Paulino et al. (1996) e Balsalobre et al. (1999) demonstraram que a inclusão de fontes protéicas nos suplementos para novilhos a pasto resultou em melhorias no desempenho dos animais. A suplementação com proteínas verdadeiras ou compostos nitrogenados não protéicos tem sido recomendada com a idéia de melhorar o aproveitamento e a utilização da forragem pastejada.

A proteína bruta apresenta correlações com a amônia, no rúmen. Concentrações acima de 5,0 mg de nitrogênio amoniacal por $100 \mathrm{~mL}$, não têm efeito no aumento da síntese de proteína microbiana (NRC, 1984). Satter \& Slyter (1974) relataram que a concentração deve estar na faixa de $5,0 \mathrm{mg} / \mathrm{dL}$ de fluido ruminal. Todavia, para Hoover (1986), esta faixa variou de 1,0 a $6,0 \mathrm{mgN} / \mathrm{dL}$, para ocorrer o máximo da atividade microbiana entretanto, Leng (1990) concluiu que, em condições tropicais, são necessárias concentrações acima de 10 e $20 \mathrm{mgN} / \mathrm{dL}$, para as respectivas maximizações da digestão ruminal da matéria seca e do consumo.

Em alguns casos, consumo e ganho de peso, podem ser incrementados pela utilização de um suplemento rico em proteína bruta; consumo de suplemento equivalente a até $0,3 \%$ de peso vivo é totalmente adicionado ao da pastagem, sem o efeito de substituição.

Dessa forma o objetivo deste trabalho foi avaliar o efeito da suplementação a pasto de novilhos Nelore inteiros, em terminação durante o período das águas.

\section{Material e Métodos}

O experimento foi realizado na Fazenda do Braga, no município de Araponga, situado na Zona da Mata do Estado de Minas Gerais, no período de janeiro a abril de 1999. A área experimental constituiu-se de, aproximadamente, 27 hectares de pastagem, com topografia plana, coberta com "braquiária do brejo" (Brachiaria radicans) na proporção de $80 \%$ e capim gordura (Melinis minutiflora) na proporção de 20\%. A área foi dividida uniformemente em três piquetes, providos de cochos cobertos de duplo acesso.

Foram utilizados 24 novilhos Nelore inteiros, com idade média de 24 meses e peso inicial de $335 \mathrm{~kg}$ $( \pm 30,60)$, escolhidos em função do grau de sangue, da idade e do peso; mais nove (9) animais foram fistulados no esôfago, sendo três (3) fistulados também no rúmen, mantidos durante todo o experimento junto aos demais; constituindo um total de 33 animais. A fase de avaliação para ganho de peso foi de 86 dias, iniciando-se em 09 de janeiro, com término em $1^{\circ}$ de abril de 1999.

Foram utilizados três suplementos comerciais: suplementação com sal mineral (SM), suplementação com sal proteinado à base de milho, farelo de trigo e uréia (MT), e suplementação com sal proteinado à base de farelos de trigo e soja (TS). Todos os animais tiveram acesso contínuo aos tratamentos e à água. Nas Tabelas 1, 2 e 3, podem ser vistas as composições percentuais destes suplementos e a sua composição químico-bromatológica.

Todos os animais foram tratados contra endo e ectoparasitas, à base de ivermectina, no início do experimento. Os pesos inicial e final foram obtidos após jejum de alimento e água de 12 horas. As pesagens intermediárias foram realizadas em intervalo de 28 dias, procedendo-se ao rodízio dos animais nos três piquetes. O delineamento utilizado foi inteiramente casualizado (DIC) e as médias, comparadas a $5 \%$, pelo teste de Student Newman-Keuls (SNK), sendo as análises realizadas utilizando-se do programa SAEG (Universidade Federal de Viçosa - UFV, 2000).

A amostragem da disponibilidade total da pastagem, foi feita com 10 quadrados metálicos $(0,5 \mathrm{~m} \mathrm{x}$ $0,5 \mathrm{~m}$ ), por piquete, e todo o material contido foi cortado rente ao solo, conforme descrito por McMeniman (1997). 
Tabela 1 - Composição dos suplementos "proteinados" utilizados

Table 1 - Composition of the used protein supplements

\begin{tabular}{|c|c|c|}
\hline $\begin{array}{l}\text { Ingredientes } \\
\text { Ingredients }\end{array}$ & $\mathrm{TS}(\%)$ & $\operatorname{MT}(\%)$ \\
\hline Milho & - & 20,00 \\
\hline Corn & & \\
\hline Farelo de soja & 20,00 & 1,70 \\
\hline Soybean meal & & \\
\hline $\begin{array}{l}\text { Farelo de algodão } \\
\text { Cotton meal }\end{array}$ & 3,75 & 2,49 \\
\hline $\begin{array}{l}\text { Farelo de trigo } \\
\text { Wheat meal }\end{array}$ & 25,82 & 15,00 \\
\hline Uréia & - & 15,00 \\
\hline $\begin{array}{l}\text { Urea } \\
\text { Fosfato bicálcico }\end{array}$ & 12,41 & 13,31 \\
\hline Dicalcium phosphate & & \\
\hline $\begin{array}{l}\text { Calcário } \\
\text { Limestone }\end{array}$ & 5,32 & 4,74 \\
\hline $\begin{array}{l}\text { Enxofre } \\
\text { Sulphur }\end{array}$ & 0,78 & 0,98 \\
\hline $\begin{array}{l}\text { Núcleo mineral } \\
\text { Mineral nucleus }\end{array}$ & 1,89 & 1,80 \\
\hline $\begin{array}{l}\text { Caulim } \\
\text { Kaolin }\end{array}$ & 10,00 & - \\
\hline $\begin{array}{l}\text { Sal } \\
\text { Salt }\end{array}$ & 20,00 & 25,00 \\
\hline
\end{tabular}

Tabela 2 - Composição da suplementação mineral (SM) utilizada

Table 2 - Composition of the used mineral supplements

\begin{tabular}{|c|c|}
\hline $\begin{array}{l}\text { Ingredientes } \\
\text { Ingredients }\end{array}$ & $\begin{array}{c}\text { Mistura mineral }(\%) \\
\text { Mineral mix }\end{array}$ \\
\hline Fosfato bicálcico & 48,65 \\
\hline Dicalcium phosphate & \\
\hline Calcário & 13,00 \\
\hline Limestone & \\
\hline Caulim & 5,19 \\
\hline Óxido de magnésio & 0,09 \\
\hline Magnesium oxide & \\
\hline $\begin{array}{l}\text { Sal } \\
\text { Salt }\end{array}$ & 29,89 \\
\hline Sulfato de cobre & 0,57 \\
\hline $\begin{array}{l}\text { Cupper sulphate } \\
\text { Monóxido de manganês }\end{array}$ & 0,04 \\
\hline Manganese monoxide & \\
\hline $\begin{array}{l}\text { Óxido de zinco } \\
\text { Zinc oxide }\end{array}$ & 0,44 \\
\hline Sulfato de cobalto & 0,09 \\
\hline $\begin{array}{l}\text { Cobalt sulphate } \\
\text { Iodato de potássio }\end{array}$ & 0,02 \\
\hline Potassium iodate & \\
\hline $\begin{array}{l}\text { Selenito de sódio } \\
\text { Sodium selenite }\end{array}$ & 0,007 \\
\hline $\begin{array}{l}\text { Micro mineral } \\
\text { Trace mineral }\end{array}$ & 2,00 \\
\hline
\end{tabular}

A amostragem da pastagem selecionada foi feita por meio da coleta de extrusa, segundo método descrito por McMeniman (1997). Foram utilizados nove novilhos Nelore inteiros, com pesos semelhantes aos do lote, providos de fístulas esofágicas, sendo três deles fistulados no rúmen, estes animais foram mantidos junto aos demais nos piquetes (três por piquete), por todo a avaliação.

As amostragens da extrusa tiveram início no quarto dia de cada período experimental. No dia anterior, os novilhos foram recolhidos ao curral, onde passaram a noite, para jejum de, aproximadamente, 12 horas. No dia de coleta, às 7 h, foi retirada a cânula esofágica e colocadas as bolsas coletoras. Os animais foram monitorados durante 30-40 minutos, sem que se interferisse no comportamento de pastejo.

As amostras foram secas em estufas ventiladas a $65^{\circ} \mathrm{C}$, por 72 horas, e processadas em moinhos do tipo Willey, com peneira de malha de $1 \mathrm{~mm}$. Posteriormente, procedeu-se às análises bromatológicas de cada amostra, a fim de se determinar o teor de matéria seca (MS), proteína bruta (PB) e extrato etéreo (EE), conforme técnicas descritas por Silva (1998), fibra em detergente neutro (FDN) e ácido (FDA), celulose (CEL), lignina (LIG), e cinzas (CZ), segundo técnica descrita por Van Soest et al. (1991). A digestibilidade in vitro da matéria seca (DIVMS) foi determinada pela técnica de Tilley \& Terry (1963). Os carboidratos totais (CHOT) foram obtidos por intermédio da equação: $100-(\% \mathrm{~PB}+\% \mathrm{EE}+\% \mathrm{CZ})$,

Tabela 3 - Composição químico-bromatológica dos suplementos

Table 3 - Composition chemical of the supplements

\begin{tabular}{lrrr}
\hline $\begin{array}{l}\text { Componentes } \\
\text { Components }\end{array}$ & SM & NA & NS \\
\hline PB $(C P)(\%)$ & & & \\
EE (\%) & - & 14,50 & 48,00 \\
FDN (NDF) (\%) & - & 1,26 & 1,37 \\
FDA (ADF) (\%) & - & 33,37 & 15,86 \\
Lignina (Lignin) (\%) & - & 14,99 & 5,46 \\
Celulose (Cellulose) $(\%)$ & - & 2,81 & 0,60 \\
Cinzas (Ashes) (\%) & 89,91 & 5,88 & 1,45 \\
Ca (\%) & 16,40 & 5,00 & 42,58 \\
P(\%) & 9,00 & 2,70 & 4,92 \\
Na (\%) & 11,70 & 7,84 & 2,70 \\
S (\%) & 0,35 & 1,20 & 1,26 \\
Cu (ppm) & 2112,00 & 709,98 & 675,00 \\
Zn (ppm) & 6400,00 & 1893,27 & 1800,00 \\
Se (ppm) & 53,00 & 14,20 & 13,50 \\
\hline
\end{tabular}


segundo Sniffen et al. (1992). A composição bromatológica da extrusa, pode ser vista na Tabela 4.

$\mathrm{O}$ consumo de MS foi determinado por meio da relação entre a quantidade de matéria seca fecal excretada e a digestibilidade do pasto. Foram utilizados três novilhos Nelore fistulados no rúmen (um por piquete), sendo que cada um recebeu óxido crômico $\left(\mathrm{Cr}_{2} \mathrm{O}_{3}\right)$, como indicador externo, acondicionado em cartucho de papele aplicado diretamente no rúmen em duas doses diárias de $5 \mathrm{~g}$, num total de $10 \mathrm{~g} /$ dia, administrados às 8 e $17 \mathrm{~h}$. Como indicador interno, foi utilizada a fibra em detergente neutro indigerível(FDNi).

Durante cinco dias (do oitavo ao décimo terceiro dia), foram realizadas coletas das fezes diretamente no reto, nos mesmos horários da aplicação do $\mathrm{Cr}_{2} \mathrm{O}_{3}$, em quantidade aproximada de $300 \mathrm{~g}$. Posteriormente, estas amostras foram compostas com base no peso seco ao ar, por tratamento e período, e analisadas quanto aos teores de cromo, em espectrofotômetro de absorção atômica, conforme metodologia descrita por Willians et al. (1962). Para a determinação da produção fecal, utilizou-se a fórmula:

$$
\mathrm{PF}=\mathrm{OF} / \mathrm{COF}
$$

em que $P F$ é a produção fecal diária (g/dia); $O F$, óxido crômico fornecido (g/dia); e $C O F$, a concentração de óxido crômico nas fezes (g/gMS).

Tabela 4 - Teores médios de matéria seca (MS), proteína bruta $(P B)$, extrato etéreo (EE), fibra em detergente neutro (FDN) e ácido (FDA), celulose (CEL) e lignina (LIG) e digestibilidade in vitro da matéria seca (DIVMS), fibra em detergente neutro indigerível (FDNi), cinzas (CZ) e carboidratos totais (CHOTS) das amostras de extrusa, no período de janeiro a abril de 1999

Table 4 - Average contents of dry matter (DM), crude protein $(C P)$, ethereal extract $(E E)$, neutral detergent fiber (NDF), acid detergent fiber (ADF), cellulose (CEL), in vitro dry matter disapperance (IVMSD), neutral detergent fiber indigestibility (NDFi), ashes (CZ) and total carbohydrates (CHOTS) of the extrusa samples, from January to April 1999

\begin{tabular}{lr}
\hline Item & $\%$ \\
\hline $\mathrm{MS}(D M)$ & 11,49 \\
$\mathrm{~PB}^{1}(C P)$ & 8,92 \\
$\mathrm{EE}^{1}$ & 2,83 \\
$\mathrm{FDN}^{1}(N D F)$ & 76,22 \\
$\mathrm{FDA}^{1}(A D F)$ & 42,77 \\
$\mathrm{CEL}^{1}$ & 30,11 \\
$\mathrm{LIG}^{1}$ & 10,65 \\
$\mathrm{DIVMS}^{1}($ IVDMD) & 58,13 \\
$\mathrm{FDNi}^{1}$ (NDFi) & 26,56 \\
$\mathrm{CZ}^{1}$ & 2,87 \\
$\mathrm{CHOTS}^{1}$ & 85,27 \\
\hline
\end{tabular}

$1 \%$ na MS (\% DM).

R. Bras. Zootec., v.32, n.1, p.214-221, 2003
Para a determinação do consumo de matéria seca (CMS) da pastagem, utilizou-se o indicador interno FDNi, adotando-se o procedimento único, seqüencial, conforme descrito e adaptado por Cochran et al. (1986). Incubaram-se $500 \mathrm{mg}$ de amostra (extrusa e fezes), por 144 horas, a $39 \pm 0,3^{\circ} \mathrm{C}$, em frascos contendo $25 \mathrm{~mL}$ de saliva artificial de McDoughal (McDoughal, 1949) e $25 \mathrm{~mL}$ de líquido ruminal (proporção de 1:1), com posterior tratamento térmico utilizando-se a solução de detergente neutro, durante uma hora. $\mathrm{Na}$ filtragem, foram utilizados cadinhos de porosidade número zero, previamente secos e tarados.

O consumo de matéria seca foi obtido da seguinte forma:

$$
\mathrm{CMS}=\mathrm{PF} * \mathrm{CIFZ} / \mathrm{CIFR}
$$

em que $C M S$ é o consumo de matéria seca ( $\mathrm{kg} / \mathrm{dia})$; $P F$, a produção fecal; $C I F Z$, a concentração do indicador nas fezes (g/gMS); e CIFR, a concentração do indicador na forragem (extrusa) (g/gMS).

A amostragem do material do rúmen, para a determinação do $\mathrm{pH}$ e da amônia ruminal, foi realizada no $20^{\circ}$ dia do último período experimental. A coleta do líquido ruminal foi feita nos tempos 0, 2, 4, 6 e 12 horas após o fornecimento do suplemento, preferencialmente entre as fases sólida e líquida do ambiente ruminal, com filtragem em camada tripla de gazes, e submetida à análise em peagâmetro digital. Após a avaliação do $\mathrm{pH}$, uma alíquota de $40 \mathrm{~mL}$ foi acondicionada em recipiente de vidro contendo $1 \mathrm{~mL}$ de ácido clorídrico $(\mathrm{HCl}) 1: 1$ e congelada a $-10^{\circ} \mathrm{C}$, para posteriores análises de $\mathrm{N}$-amoniacal.

O líquido ruminal foi descongelado e imediatamente centrifugado a $3.000 \mathrm{rpm}$ durante 10 minutos, sendo recolhido o sobrenadante para análise do teor de nitrogênio amoniacal, pelo método de Kjeldahl, segundo Fenner, citado por Vieira (1980). Utilizou-se uma alíquota de $2,0 \mathrm{~mL}$ do sobrenadante e $10,0 \mathrm{~mL}$ de $\mathrm{KOH}(2 \mathrm{~N})$ para a destilação, sendo o destilado $(100,0 \mathrm{~mL})$ recolhido em erlemeyer contendo $10,0 \mathrm{~mL}$ de ácido bórico; a titulação foi feita utilizando-se ácido clorídrico 0,005 N.

As análises estatísticas foram realizadas, em delineamento inteiramente casualizado, adotando-se o esquema de parcelas subdivididas, no qual os suplementos eram as parcelas e o tempo, as subparcelas. As médias foram comparadas a $5 \%$ de probabilidade pelo teste SNK. Também foram ajustadas equações de regressão, em função do tempo de coleta. O pacote estatístico utilizado foi o SAEG (Universidade Federal de Viçosa, 2000) 


\section{Resultados e Discussão}

Os resultados referentes ao peso corporal e ganho médio diário (GMD) dos novilhos, em função dos diferentes suplementos, são apresentados na Tabela 5 . Não houve diferença entre os suplementos protéicos TS e MT. A suplementação protéica aumentou o desempenho de bovinos, devido ao incremento do consumo e da digestibilidade, elevando, assim, a utilização dos nutrientes (Owens, 1991, citado por Balsalobre et al., 1999).

Foram detectados problemas com o tipo de pastagem utilizada (B. radicnas), como casos de intoxicação. Os principais sintomas apresentados Moraes (1995) foram urina com coloração escura, fezes diarréicas, debilidade, andar desequilibrado, mucosas pálidas e micção freqüente, podendo levar ao emagrecimento, e aparecem entre a primeira e a quarta semana, sendo extremamente raros os casos fatais. Dez animais deste experimento, principalmente aqueles suplementados com SM, apresentaram tais sintomas, o que pode ter interferido no ganho de peso de certos animais.

A determinação de consumo, com base em constituintes indigestíveis, ou mesmo com os indicadores

Tabela 5 - Médias para pesos vivos inicial (PVI) e final (PVF), ganhos médios diários (GMD) e consumo de suplementos (CSUP), expressos em kg/ dia, em função dos diferentes tratamentos

Table 5 - Averages of the initial live weight (ILW) and final (FLW), average daily gain (ADG) and intake of supplements (ISUP), expressed in $\mathrm{kg} /$ day, in fuction of the different treatments

\begin{tabular}{lcccc}
\hline & \multicolumn{3}{c}{ Tratamentos } & CV \\
& Treatments & \\
\cline { 2 - 4 } & SM & TS & MT & \\
\hline PVI $(I L W)(\mathrm{kg})$ & 341 & 327 & 339 & 9,33 \\
PVF $(F L W)(\mathrm{kg})$ & 388 & 389 & 437 & 8,55 \\
GMD $(A D G)(\mathrm{kg} / \mathrm{dia})$ & $0,60 \mathrm{~b}$ & $0,76 \mathrm{ab}$ & $0,88 \mathrm{a}$ & 26,65 \\
CSUP $(I S U P)(\mathrm{kg} / \mathrm{dia})$ & 0,13 & 0,23 & 0,20 & - \\
\hline
\end{tabular}

Médias, na linha, seguidas de letras diferentes diferem entre si $(P>0,05)$ pelo teste SNK.

Means, in a row followed dy different letters are different by SNK test $(P>$.05).

${ }^{1} \mathrm{SM}=$ mistura mineral; TS = sal "proteinado" à base de farelo de trigo e farelo de soja; MT = sal "proteinado" à base de milho, farelo de trigo e uréia.

1 SM = mineral supplement; TS = protein salt of wheat meal and soybean meal; $M T=$ protein salt of ureia, corn and soybean meal.

\footnotetext{
R. Bras. Zootec., v.32, n.1, p.214-221, 2003
}

internos, quando se trabalha com situações sujeitas a alterações na digestibilidade da pastagem melhor se assemelha ao consumo animal. O uso da FDNi, obtida após 144 horas de incubação in vitro, apresentou valores semelhantes à coleta total de fezes (Berchielli et al., 1996; Detmann, 2001a). Neste trabalho, os valores médios encontrados para o consumo de forragem foram baixos, evidenciando o estresse e o excesso de manipulação dos animais que estavam pastejando junto com os animais fistulados, já que as coletas eram feitas duas vezes ao dia, e para issos era necessário a movimentação de todos os 33 animais.

As disponibilidades totais de pasto de $6.967 \mathrm{e}$ $6.427 \mathrm{~kg}$ de MS, para o período de fevereiro e março, foram superiores à encontrada por Minson (1990) e Euclides et al. (1998), de $2000 \mathrm{~kg}$ de MS, como limitante para o consumo de forrageiras. Os animais que receberam suplementação com alto teor de nitrogênio degradável no rúmen (MT) apresentaram consumo constante entre os períodos e superior àqueles suplementados apenas com mistura mineral. Este incremento pode ser definido pela maior potencialização dos microrganismos digestores de fibra. Detmann et al. (2001b), suplementando animais em pastagem de B. brizantha, com milho e farelo de soja farelos de trigo e de soja; concluíram que a suplementação não influi no consumo de forragem. Portanto, o melhor desempenho dos animais, em função de uma suplementação protéica, pode não ser devido a mudanças no consumo, mas sim às alterações de digestibilidade ou eficiência na utilização dos nutrientes, incluindo efeitos da proteína degradada e não-degradada no rúmen.

Zervoudakis (2001), suplementando animais mestiços a pasto com $0,5 \mathrm{~kg} /$ dia milho e farelo de soja e milho e farelo de glúten de milho, obteve ganhos semelhantes $(0,92$ e $0,88 \mathrm{~kg} / \mathrm{dia})$, mas superiores ao deste trabalho $(0,77 \mathrm{~kg} / \mathrm{dia})$, para animais alimentados com proteína não-degradada no rúmen, sem controladores de consumo. Kabeya (2002), em condições semelhantes, não encontrou diferenças entre os animais suplementados com milho e farelo de trigo $(0,88$ e $0,80 \mathrm{~kg} / \mathrm{dia})$. Elizalde et al. (1998) observaram, em novilhos consumindo $1,4 \mathrm{~kg}$ de milho quebrado ou 1,4 kg de farelo de glúten, ganhos de 0,77 e 0,69 $\mathrm{kg} / \mathrm{d}$ e eficiência alimentar pior que a obtida no presente trabalho, sem reguladores de consumo. Possivelmente, devido às altas taxas de substituição, os animais reduziram o consumo de forragem, em detrimento aos suplementos. Balsalobre et al. (1999), 
trabalhando com suplementos proteinados comerciais de baixo consumo, contendo teores de 25,0 e $46,1 \%$ de PB, verificaram que os animais suplementados apenas com minerais apresentaram ganho $(0,57 \mathrm{~kg} / \mathrm{d})$ semelhante ao deste trabalho, mas aqueles que consumiram o suplemento contendo uréia não apresentaram diferenças em desempenho daqueles suplementados sem uréia $(0,70$ e $0,64 \mathrm{~kg} / \mathrm{d})$, conforme o presente trabalho.

Contudo, para o presente trabalho, verificou-se maior GMD para os novilhos suplementados com uréia (MT), o que possivelmente dependeu do maior conteúdo protéico deste suplemento, apesar de seu consumo $(0,20 \mathrm{~kg} / \mathrm{dia})$ ter sido inferior à TS $(0,23 \mathrm{~kg} /$ dia), proporcionando ingestão de proteína via suplemento $34,8 \%$ superior. Quando comparado à suplementação mineral (SM), o suplemento contendo uréia permitiu ganhos superiores em torno de $48 \%$ (280 g/dia), porém, quando comparado à TS, não diferiu significativamente.

As análises de $\mathrm{pH}$ e $\mathrm{N}-\mathrm{NH}_{3}$ apresentaram efeito $(\mathrm{P}<0,01)$ para suplemento, tempo de coleta e interação tempo x suplemento. Então, procedeu-se à análise do desdobramento da interação. As equações de regressão ajustadas em função do tempo, bem como os valores médios de $\mathrm{pH}$, estão na Tabela 6. Os animais suplementados com MT apresentaram valores médios de $\mathrm{pH}$ superiores aos demais, principalmente, quando comparados ao SM. Estes valores foram superiores aos encontrados por Detmann (2001b), que variaram de 6,5 a 6,3 , quando suplementados à base de milho e farelo de soja. Zervoudakis (2001) não encontrou influência entre os tempos de coleta $(0$, 2, 4 e 6 horas), sendo o menor valor de 6,2. Caton \& Dhuyrvetter (1997) afirmaram que a queda de $\mathrm{pH}$ está vinculada ao nível de suplementação. Os valores apresentados estão acima do limite de 6,2, proposto por Hoover et al. (1986) e Orskov (1988), como inibitório à digestão da fibra, aos microrganismos celulolíticos e à fermentação ruminal (Russell \& Wilson, 1996). O ponto mínimo estimado foi de 7,17 para os animais suplementados com MT. Para os tempos 0 e 2 horas, não ocorreram diferenças entre os suplementos SM e TS, apesar deste ter suprido nível superior de proteína.

As equações de regressão ajustadas em função do tempo, bem como os valores de $\mathrm{N}-\mathrm{NH}_{3}$, estão na Tabela 7. Os animais suplementados com MT apresentaram maiores valores para os tempos de 0,2 e 4 horas após a suplementação. Estes valores podem
Tabela 6 - Equações de regressão ajustadas, em função do tempo, e médias de $\mathrm{pH}$ no líquido ruminal, para os diferentes tempos (horas), após o fornecimento dos suplementos

Table 6 - $\quad$ Adjusted regression equations, in function of the time, and $\mathrm{pH}$ averages in the liquid ruminal, for the different times (hours), after the supply of the supplements

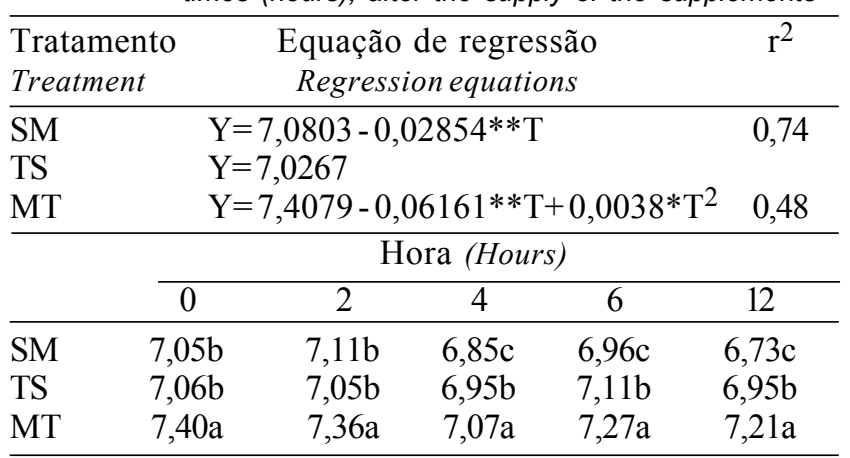

${ }^{* *}$ t significativo a $1 \%$; ${ }^{*}$ t significativo a $5 \%$.

** significant $t$ to $1 \%$; * significant at $5 \%$.

Médias seguidas por uma mesma letra, na mesma coluna, não diferem pelo teste SNK $(P>0,05)$.

Means followed by the same letters, within a column, are not different by SNK test $(P>$.05).

Tabela 7 - Equações de regressão ajustadas em função do tempo e concentrações médias de $\mathrm{N}$ $\mathrm{NH}_{3}$ (mgN/dL) no líquido ruminal, para os diferentes tempos (horas), após o fornecimento dos suplementos

Table 7 - Adjusted regression equations in function of the time and medium concentrations of $\mathrm{N}-\mathrm{NH}_{3}(\mathrm{mgN} / \mathrm{dL})$ in the liquid ruminal, for the different times (hours), after the supply of the supplements

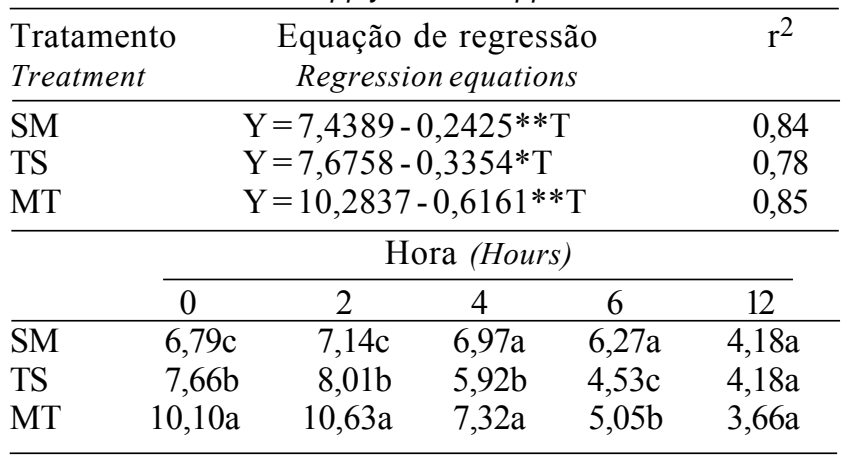

${ }^{* *}$ t significativo a $1 \%$; ${ }^{*}$ t significativo a $5 \%$.

** significant $t$ to $1 \%$; * significant at $5 \%$.

Médias seguidas por uma mesma letra, na mesma coluna, não diferem pelo teste SNK $(P>0,05)$.

Means followed by the same letters, within a column, are not different by SNK test $(P>05)$. 
ser atribuídos à maior degradação da uréia. No tempo de 12 horas, as concentrações de $\mathrm{N}$-amoniacal foram inferiores ao mínimo de $5 \mathrm{mgN} / \mathrm{dl}$, sugerido pelo NRC (1996) e por Satter \& Slyter (1974), como nível ótimo para a degradação ruminal da matéria seca. Leng (1990) concluiu que, em condições tropicais, são necessárias concentrações acima de $10 \mathrm{mgN} / \mathrm{dL}$, para que haja maximização da digestão ruminal da matéria seca. Apenas o tratamento MT, nos tempos de 0 e 2 horas após a alimentação, obtiveram esta concentração, que deve ser superior a $20 \mathrm{mg} / \mathrm{dL}$ para que ocorra maximização do consumo; nenhum dos tempos apresentaram tais concentrações.

\section{Conclusões}

Os animais que receberam suplementação protéica, no período das águas, apresentaram melhor desempenho, quando comparados aos que receberam a suplementação mineral.

$\mathrm{O} \mathrm{pH}$ e a amônia ruminal mantiveram-se dentro dos limites biológicos aceitáveis.

\section{Literatura Citada}

BALSALOBRE, M.A.A.; SANTOS, P.M.; CORSI, M. et al. Desempenho de novilhos em crescimento recebendo suplementação a pasto durante o verão. In: REUNIÃO ANUAL DA SOCIEDADE BRASILEIRA DE ZOOTECNIA, 36., 1999, Porto Alegre. Anais... São Paulo:Gmosis, 1999, 17 par. CD-ROM. Nutrição de ruminantes. Bezerros e gado leiteiro. NUR-031.

BERCHIELLI, T.T.; MAURO, F.R.C.; FURLAN, C.L. et al. Avaliação de indicadores internos para a determinação da digestibilidade da matéria seca. In: REUNIÃO ANUAL DA SOCIEDADE BRASILEIRA DE ZOOTECNIA, 33., 1996, Fortaleza. Anais... Fortaleza: Sociedade Brasileira de Zootecnia, 1996. p.44-45.

CATON, J.S.; DHUYRVETTER, D.V. Influence of energy supplementation on grazing ruminants: requirements and responses. Journal of Animal Science, v.75, p.533-542. 1997

OCHRAN, R.C.; ADAMS, D.C.; WALLACE, J.D. et al. Predicting digestibility of different diets with internal markers: evaluation of fours potential markers. Journal Animal Science, v.63, p.1476, 1986.

DETMANN, E.; PAULINO, M.P.; ZERVOUDAKIS, J.T. et al. Cromo e indicadores internos na determinação do consumo de novilhos mestiços, suplementados a pasto. Revista Brasileira de Zootecnia, v.30, n.5, p.1600-1609, 2001 a.

DETMANN, E.; PAULINO, M.F.; ZERVOUDAKIS, J.T. et al. Suplementação de novilhos mestiços durante a época das águas: parâmetros ingestivos e digestivos. Revista Brasileira de Zootecnia, v.30, n.5, p.1600-1609, 2001b.

ELIZALDE, J.C.; CREMIN, F.D.; FAULKNER, D.B. et al. Performance and digestion by steers grazing tall fescue and supplement with energy and protein. Journal of Animal Science, v.76, p.1691-1701, 1998.

R. Bras. Zootec., v.32, n.1, p.214-221, 2003
EUCLIDES, V.P.B. Valor alimentício de espécies forrageiras do gênero Panicum. In: SIMPÓSIO SOBRE MANEJO DE PASTAGENS, 12., 1995. Piracicaba. Anais... Piracicaba: FEALQ, 1995. p.245-273.

EUCLIDES, V.P.B.; EUCLIDES FILHO, K.; ARRUDA, Z.J. et al. Desempenho de novilhos em pastagem de Brachiária decumbens submetidos a diferentes regimes alimentares. Revista Brasileira de Zootecnia, v.27, n.2, p.246-254, 1998.

HOOVER, W.H. Chemical factors involved in ruminal fiber digestion. Journal of Dairy Science, v.69, p.2755-2766, 1986.

KABEYA, K.S.; PAULINO, M.P.; DETMANN, E. et al. Suplementação de novilhos mestiços em pastejo na época de transição água-seca: desempenho produtivo, características físicas de carcaça, consumo e parâmetros ruminais. Revista Brasileira de Zootecnia, v.31, n.1, p.213-222, 2002.

LANA, R.P.; RUSSELL, J.B.; Van AMBURGH, M.E. The role of $\mathrm{pH}$ in regulating ruminal methane and ammonia production. Journal Animal Science, v.76, p.2190-2196, 1998.

LENG, R.A. Factors affecting the utilization of "poor-quality" forages by ruminants particulaty under tropical conditions. Nutrition Research and Review, v.3, n.3, p.277-303. 1990.

McDOUGHAL, E.I. Studies on ruminal saliva. 1.The composition and output of sheep saliva. Biochemistry Journal, v.43, n.1, p.99-109, 1949

McMENIMAN, N.P. Methods of estimating intake of grazing animals. In: REUNIÃO ANUAL DA SOCIEDADE BRASILEIRA DE ZOOTECNIA/ SIMPÓSIO SOBRE TÓPICOS ESPECIAIS EM ZOOTECNIA., 1997, 34., Juiz de Fora. Anais... Juiz de Fora: Sociedade Brasileira de Zootecnia, 1997. p.131-168.

MINSON, D.J. Forage in ruminant nutrition. New York: Academy Press. 1990. 483p.

MORAES, Y.J.B. Forrageiras: conceitos, formação e manejo. Guaíba: Agropecuária, 1995. 215p.

NATIONAL RESEARCH COUNCIL - NRC. Nutrient requirements of beef cattle. Washington, D.C.: National Academy Press, 1984. 91p.

NATIONAL RESEARCH COUNCIL - NRC. Nutrient requirements of beef cattle. Washington, D.C.: National Academy Press, 1996. 242p.

NOLLER, C.A.; NASCIMENTO Jr., D.; QUEIROZ, D.S. Exigências nutricionais de animais em pastejo. In: SIMPÓSIO SOBRE MANEJO DE PASTAGENS, 13, 1996, Piracicaba. Anais... Piracicaba: Fundação de Estudos Agrários Luiz de Queiroz, 1997. p.151-184.

ORSKOV, E.R. Nutrición proteica de los ruminantes. Zaragoza: Acribia. 1988. 178p.

PAULINO, M.F. Misturas múltiplas na nutrição de bovinos de corte a pasto. In: SIMPÓSIO GOIANO SOBRE PRODUÇÃO DE BOVINOS DE CORTE, 1999, Goiânia. Anais... Goiânia: Colégio Brasileiro de Nutrição Animal, 1999. p.95-105.

PAULINO, M.F.; REHFELD, O.A.M.; RUAS, J.R.M. et al. Alguns aspectos da suplementação de bovinos de corte em regime de pastagem durante a época da seca. Informe Agropecuário, v.89, n.89, p.28-31, 1982.

PAULINO, M.F.; RUAS, J.R.M. Considerações sobre recria de bovinos de corte. Informe Agropecuário, v.153/154, p.68-80, 1988.

PAULINO, M.P.; BORGES, L.E.; CARVALHO, P.P. et al. Fontes de proteína em suplementos múltiplos sobre o desempenho de novilhos e novilhas mestiços em pastoreio durante a época das águas. In: REUNIÃO ANUAL DA SOCIEDADE BRASILEIRA DE ZOOTECNIA, 33., 1996, Fortaleza. Anais... Fortaleza: Sociedade Brasileira de 
Zootecnia, 1996. p.12-13.

POPPI, D.P., McLENNAN, S.R. Protein and energy utilization by ruminants at pasture. Journal Animal Science, v.73, n.1, p.278-290, 1995.

RUSSELL, J.B.; WILSON, D.B. Why are ruminal cellulolytic bacteria unable to digest cellulose at low $\mathrm{pH}$ ? Journal Dairy Science, v.79, p.1503-1509, 1996.

SATTER, L.D.; SLYTER, L.L. Effect of ammonia concentration on rumen microbial protein production "in vitro". British Journal Nutrition, v.32, p.199, 1974.

SILVA, D.J. Análise de alimentos (Métodos químicos e biológicos). 2.ed. Viçosa: Universidade Federal de Viçosa, 1998. 165p.

SNIFFEN, C.J.; O'CONNOR, J.D.; Van SOEST, P.J. et al. A net carbohydrate and protein system for evaluating cattle diets: II- Carbohydrate and protein availability. Journal of Dairy Science, v.70, p.562-3577, 1992.

TILLEY, J.M.A.; TERRY, R.A. A two-stage technique for the in vitro digestion of forages crops. Journal British Grassland Society, v.18, n.2, p.104-111, 1963.

UNIVERSIDADE FEDERAL DE VIÇOSA - UFV. 2000. SAEG - Sistema de análises estatísticas e genéticas. Versão 8.0. Viçosa, MG. 142p. (Manual do usuário).
Van SOEST, P.J.; ROBERTSON, J.B.; LEWIS, B.A. Methods for dietary fiber, and nonstarch polyssacarides in relations to animal nutrition. Journal of Dairy Science, v.74, n.10, p.3583-3597, 1991.

VIEIRA, P.F. Efeito do formaldeído na proteção de proteínas e lípídeos em rações. Viçosa, MG: Universidade Federal de Viçosa, 1980.98p. Tese (Doutorado em Zootecnia) - Universidade Federal de Viçosa, 1980.

WILLIANS, C.H.; DAVID, D.J.; IISMAA, O. The determination of chromic oxide in feces samples by atomic absorption spectrophotometry. Journal of Agricultural Science, v.59, p.381-385, 1962.

ZERVOUDAKIS, J.T.; PAULINO, M.P.; DETMANN, E. et al. Desempenho, características de carcaça de novilhos suplementados no período das águas. Revista Brasileira de Zootecnia, v.30, n.4, p.1381-1389, 2001.

Recebido em: 27/03/01

Aceito em: 20/08/02 